\title{
Discurso e retórica: sobre o procedimento reductio ad Hitlerum
}

\section{Discourse and rhetoric: on the reductio ad Hitlerum procedure}

João Kogawa

Unifesp

jmmkogawa@gmail.com

Renan Mazzola

Unicentro Guarapuava

mazzola.renan@gmail.com

Resumo: Este trabalho objetiva compreender o funcionamento retóricodiscursivo da estratégia argumentativa reductio ad Hitlerum, empregada por Frei Betto para comparar o regime nazista constituído na Alemanha dos anos 1920 e a Bancada Evangélica que compõe uma parte do Congresso Nacional brasileiro atualmente. Este trabalho se debruça sobre a expressão "ovo da serpente", empregada na comparação construída por meio da metáfora e da metonímia. O arcabouço teórico é constituído pela Retórica clássica (Aristóteles), pela Retórica contemporânea (Angenot), por reflexões derivadas de Jakobson e pela Análise do Discurso de linha francesa (Pêcheux). O sofisma reductio ad Hitlerum se caracteriza por despertar a cólera dos interlocutores, pois não há motivos racionais ou lógicos para se concordar com esse argumento emocional.

Palavras-chave: retórica; Análise do Discurso; reductio ad Hitlerum; argumentação; debate. 
Abstract: This paper aims to understand the rhetorical-discursive functioning of the reductio ad Hitlerum argumentative strategy, which was employed by Frei Betto to compare the Nazi regime that took place in Germany in the 1920s and the evangelical bench that comprises part of the current Brazilian National Congress. This work focuses on the expression "serpent's egg", employed in a comparison constructed through metaphor and metonymy. The theoretical framework consists of classical Rhetoric (Aristotle), contemporary Rhetoric (Angenot), Jakobson's reflexions and French Discourse Analysis (Pêcheux). The Reductio ad Hitlerum procedure is characterized by awakening the wrath of interlocutors, because there is no rational or logical reasons to agree with this emotional argument.

Keywords: rhetoric; Discourse Analysis; reductio ad Hitlerum; argumentation; debate.

Recebido em 15 de julho de 2015. Aprovado em 02 de março de 2016.

\section{Introdução}

Fiorin (2014a) nos diz que a atualidade da retórica se encontra no fato de que todos os discursos, mesmo os científicos, são dotados de uma retoricidade. Isso faz do tratado elaborado por Aristóteles uma obra fundamental para as atuais investigações sobre o discurso. Com efeito, o caráter geral da retoricidade dos discursos abre uma enorme possibilidade para abordarmos o objeto que se nos apresenta: o discurso político-religioso dirigido por Frei Betto à chamada Bancada Evangélica do Congresso Nacional, pronunciado em 16 de novembro de 2013 no $9^{\circ}$ Encontro Nacional Fé e Política, realizado em Taguatinga, no campus da Universidade Católica de Brasília.

A Retórica clássica, retomada de Aristóteles (2013), a Retórica contemporânea, tal como a desenvolve Marc Angenot (2010;2012;2013), as reflexões derivadas de Fiorin (2014a; 2014b) e da escola francesa de Análise do Discurso, na figura de Pêcheux (2011), compõem o quadro teórico que subsidiará nossas problematizações e análises. A mobilização desse arcabouço objetiva tanto analisar os processos internos aos sistemas 
da língua quanto compreender o funcionamento dos aspectos externos da linguagem e a maneira pela qual eles influenciam na produção do sentido.

Sob esse prisma, associando questões atinentes à Retórica e à Análise do Discurso de linha francesa, procuramos analisar a construção do sintagma "ovo da serpente", atribuído por duas matérias de cunho jornalístico à figura de Frei Betto como metáfora da "gestação do mal" ou da "latência do mal" e como metonímia do tempo futuro: o "ovo da serpente" é, por extensão e expansão de seu sentido, o símbolo do devir, ou seja, uma metonímia construída pela discursivização do próprio símbolo em relação àquilo que ele simboliza.

Além desse aspecto semântico "interno" à expressão, que é composta, portanto, pela metáfora do mal e pela metonímia do tempo, podemos destacar uma configuração semântica que lhe é "externa": o funcionamento do interdiscurso. Por meio do exercício interdiscursivo, o sintagma nominal sobre o qual nos debruçamos encontra eco em dois outros lugares de memória: na tragédia Júlio César, de Shakespeare, escrita em 1599, e no filme intitulado pela expressão, O ovo da serpente, de Ingmar Bergman, rodado em 1977.

Nossa investigação objetiva, nesse sentido, analisar a construção de um discurso e a mobilização de estratégias retóricas para que o enunciador - ou o orador, a posição ou a instância enunciativa - atinja os efeitos desejados. Esses efeitos são alcançados a partir de elementos internos e externos ao enunciado. Nosso exercício de análise se utiliza tanto do microscópio quanto do telescópio para coletar variados elementos que nos auxiliam na compreensão do objeto de linguagem estudado.

A construção do discurso direcionado à Bancada Evangélica por Frei Betto, ao retomar a figura do "ovo da serpente", associa-a ao nazismo por meio de um procedimento retórico denominado reductio ad Hitlerum. A partir desse procedimento, o que se faz é muito mais despertar a cólera ${ }^{1}$ do auditório contra aquelas figuras associadas a Hitler do que realizar um exercício argumentativo lógico de comprovação ou refutação de uma tese. Assim, contra aquilo que seria a representação do "ódio na política", produz-se um discurso - historicamente fundado na associação com o nazismo - calcado na mobilização da cólera pela associação da Bancada com o nazismo. Contra o ódio, utiliza-se uma estratégia que mobiliza o próprio ódio.

${ }^{1}$ Referimo-nos aqui ao modo como Aristóteles (2013) define “cólera” em sua Retórica. 
A partir dessas considerações, nossa investigação procura evidenciar como, por meio da metáfora e do interdiscurso, o discurso de uma certa "esquerda partidária" - ala a que o lugar subjetivo de Frei Betto se vincula - descredibiliza o outro por uma construção retórica que se apresenta ao mesmo tempo como referencial - o espaço de divulgação do dizer de Frei Betto tem matizes "jornalísticos" ao ser enunciado no interior de veículos com de cunho informativo -, emocional - "a Bancada Evangélica é o mal que oprime os desvalidos, as minorias etc." - e apelativa - "não votem nos candidatos dessa bancada".

Esse discurso tem como condição de produção o período préeleitoral brasileiro. Sua emergência se dá, efetivamente, alguns meses antes das eleições presidenciais de 2014 e, em função disso, há uma "atmosfera" pré-campanha política que produz efeitos de sentido próesquerda e/ou pró-Partido dos Trabalhadores (PT). Desse modo, o lugar das matérias produzidas se associa ao da religião e da política, compondo uma arena discursiva voltada para o convencimento de um auditório predisposto contra certa parcela da classe política representada por membros da classe evangélica.

O artigo apresentará três partes: a primeira objetiva contextualizar a retórica no âmbito das teorias linguísticas, a segunda define a noção de reductio ad Hitlerum a partir das teorias da argumentação contemporâneas, e a terceira verticaliza a análise retórico-discursiva do sintagma "ovo da serpente" pela mobilização dos conceitos de metáfora, metonímia e interdiscurso.

\section{A retórica no âmbito das teorias linguísticas}

Desde a Grécia Antiga, a retórica ocupou um lugar fundamental na compreensão sobre a linguagem e seu funcionamento. Nesse contexto, que remonta aproximadamente ao século V a.C., Aristóteles (2013) pondera que a arte retórica é a contraparte da dialética na medida em que esta se encarregaria do caráter verdadeiro ou falso dos enunciados em geral e aquela de sua possibilidade. Isto é, alguns silogismos (lógicos) se encarregam de constatar a factualidade, enquanto outros (retóricos) convencem a partir da possibilidade. Assim, afirmar que "João é mortal por ser homem" (silogismo lógico) é uma verdade factual, enquanto dizer que "João é corrupto por ser homem" (silogismo retórico, ou entimema) é uma possibilidade. Deriva dessa oposição a conceptualização da retórica e 
seu objeto (ARISTÓTELES, 2013): é uma arte - por oposição às ciências, como Matemática ou Astronomia - que se ocupa dos meios de persuasão.

A partir do que foi mencionado anteriormente, cabe destacar que o objeto material sobre o qual a retórica trabalha é o entimema - "a substância da persuasão retórica" (ARISTÓTELES, 2013, p. 39) - que, segundo Fiorin (2014a), pode se apresentar sob diversas materialidades (verbal, visual, verbo-visual), ainda que, por muito tempo, o objeto da retórica tenha sido, de acordo com o autor, a linguagem verbal oral.

Se a retoricidade é inerente a todo discurso, "busca-se analisar a retoricidade de toda operação de linguagem" (FIORIN, 2014a, p. 16), ou seja, qualquer enunciado produzido pode ser apreendido sob uma perspectiva retórica. Isso nos remete a outro ponto fundamental que diz respeito aos gêneros do discurso e aos modos de retoricização de cada um deles. Embora Aristóteles (2013, p. 44-45) se volte para três gêneros em particular (o deliberativo, o forense e o demonstrativo), a retórica é "o poder, diante de quase qualquer questão que nos é apresentada, de observar e descobrir o que é adequado para persuadir. E esta é a razão por que a retórica não aplica suas regras a nenhum gênero particular e definido".

Além desses três gêneros do discurso, Aristóteles (2013, p. 45) elenca três tipos de meio de persuasão supridos pela palavra falada: "o primeiro depende do caráter pessoal do orador; o segundo, de levar o auditório a uma certa disposição de espírito; e o terceiro, do próprio discurso no que diz respeito ao que demonstra ou parece demonstrar". O primeiro meio de persuasão é conhecido como a construção do ethos. $\mathrm{O}$ segundo é conhecido como a habilidade do orador em despertar paixões - pathos - na plateia. O terceiro, por fim, remete ao logos, ao próprio objeto do discurso: é nessa instância que mobilizamos os entimemas, ou silogismos retóricos.

Diversas vertentes teóricas vão se debruçar sobre um dos meios de persuasão elencados por Aristóteles e desenvolvê-los.

Sabemos que a história da disciplina não se furtou a comentar abundantemente a trilogia aristotélica do logos, do ethos, e do pathos. Dedicamo-nos essencialmente às glosas dos conceitos de Aristóteles e também ao estudo das modificações a que eles foram submetidos pelos textos de Cícero e de Quintiliano. (AMOSSY, 2008, p. 17).

A construção do ethos, por exemplo, é objeto privilegiado de investigação deAmossy (2008) para a compreensão das naturezas do discurso. A inscrição do locutor no discurso em função da construção 
de uma imagem de si é peça fundamental da máquina retórica. Esse procedimento é fortemente ligado à enunciação, colocada no centro da análise linguística pelos trabalhos de E. Benveniste. Amossy (2008, p. 14) alerta para o fato de que "nem Benveniste, nem Goffman, nem Kerbrat-Orecchioni fazem uso do termo ethos. A integração desse termo às ciências da linguagem encontra uma primeira expressão na teoria polifônica da enunciação de Oswald Ducrot".

A construção especular da imagem dos interlocutores aparece de igual maneira na obra de Pêcheux (1997, p. 82, grifos do autor), para quem A e B, nas duas pontas da cadeia de comunicação, fazem uma imagem um do outro: "o que funciona nos processos discursivos é uma série de formações imaginárias que designam o lugar que A e B se atribuem cada um a si e ao outro, a imagem que eles se fazem de seu próprio lugar e do lugar do outro".

Assim, a história da retórica conduz a um conjunto de considerações que coincidem com as preocupações atuais da pragmática. Algumas dessas preocupações ora aproximam-se, ora distanciam-se da noção de ethos. Tanto essa aproximação quanto esse distanciamento vão caracterizar a identidade de certas escolas de análise linguística. Mencionamos acima a figura de $\mathrm{O}$. Ducrot e de sua teoria polifônica da enunciação. Podemos lembrar, por outro lado, de C. Perelman, "autor que em nossa época inovou o estudo da retórica ao mostrar o lugar central, em diversas disciplinas (do direito à filosofia, passando pela literatura) da arte de persuadir". (AMOSSY, 2008, p. 19).

No campo das teorias da argumentação contemporâneas, destaca-se ainda a figura de Angenot $^{2}$ (1982) que, a partir da cronologia apresentada anteriormente, retoma, em sua obra, a construção de uma imagem de si no discurso. Essa construção possui um lugar limitado na obra de C. Perelman e é resgatada em La parole pamphlétaire (1982), que reúne ainda os estudos argumentativos e a teoria dos atos de fala da linguagem presentes em Austin e Searle.

Ainda no âmbito das teorias linguísticas, podemos encontrar em Jakobson uma importante aproximação com a retórica. Ao retomar o par sintagma (contíguo) $\times$ paradigma (similar), o autor russo define as bases para a reflexão sobre os dois tropos fundamentais para construção das figuras de retórica: a similaridade e a contiguidade. $\mathrm{O}$ primeiro desses

${ }^{2}$ Voltaremos a esse autor mais adiante. 
tropos se associa à metáfora e o segundo à metonímia: "Jakobson funda uma semântica de base, em que os sentidos são gerados metafórica e metonimicamente". (FIORIN, 2014a, p. 15).

Fiorin (2014a, p. 28) define, a partir de Aristóteles, Ricoeur, Jakobson e da Semiótica francesa, as "bases para um estudo das figuras". Grosso modo, a retórica se encarrega de impropriedades, pois a construção do sentido ornamentado estabelece uma inadequação semântica a certas imposições convencionais da língua: "A noção de impropriedade implica inadequação predicativa e construção de propriedades semânticas que dão uma existência autônoma à inovação semântica" (FIORIN, 2014a, p. 29).

É a partir desse postulado central que o autor propõe uma classificação das figuras que se desenvolvem a partir de uma premissa jakobsoniana, segundo a qual os tropos - as "direções semânticas" - são construídos a partir de duas direções centrais: a expansão metonímica e a condensação metafórica. Acreditamos que essa base teórica nos ajuda a compreender o que Strauss (2014) define como reductio ad Hitlerum, ou seja, uma construção retórica que objetiva desqualificar o argumento do outro comparando-o ou associando-o a Hitler, à Gestapo ou ao fascismo.

Essa é uma estratégia evocada nas sequências discursivas analisadas adiante para se dirigir à Bancada Evangélica e a figuras polêmicas como o pastor Silas Malafaia. Ao afirmar que "estamos assistindo certos segmentos religiosos começarem a chocar o ovo da serpente", o sujeito desse discurso inscreve-se em uma posição que rotula a Bancada Evangélica e, por extensão, seus eleitores como difusores do ódio ou da discórdia e, contra eles, é necessária uma campanha para evitar uma nova ocorrência do nazismo - em estado germinal -, agora em território brasileiro. Quando se trata desses sujeitos, os temas em debate são sempre polêmicos e a síntese de suas posições, quando enunciadas por seus oponentes, é a intolerância.

Nas redes sociais, uma série de comentários a respeito das ideias "dos evangélicos" pode ser visualizada sem grandes dificuldades. Entre outros aspectos, o que ressalta a força da estratégia retórica reductio ad Hitlerum é a generalização das posições de alguns líderes, que se dizem evangélicos, a todos os evangélicos. Assim, o entimema "Hitler defendia x, então x é uma ideia maligna" figura como aplicável sempre que um evangélico se manifesta. Poderíamos preencher " $x$ " com a expressão "odiar abacaxis": "Hitler odiava abacaxis, então odiar abacaxis é uma ideia maligna". 
Trata-se de algo que se tornou, após a Segunda Guerra Mundial, um lugar-comum e, segundo Aristóteles, é justamente a partir de lugarescomuns que o argumento retórico se constrói. Inclusive, o autor pontua os principais lugares-comuns a serem explorados pelo orador. Trata-se daquilo que é mais ou menos aceito em uma determinada comunidade e que, se evocado por um entimema, tem maior probabilidade de aceitação. Hoje, por exemplo, poderíamos considerar um lugar-comum o fato de Hitler ter sido um ser maléfico. Assim, sempre que alguém é associado a ele ou a suas ações, esse alguém será considerado maléfico. Desse modo, quando uma notícia jornalística afirma que a Bancada Evangélica é o "ovo do nazismo", ou quando retoma e atribui expressões à figura pública de Frei Betto, tais como: "ovo da serpente", "fascismo" etc., trata-se de um procedimento de metaforização que desconstrói, pela mobilização da cólera, o argumento do outro ${ }^{3}$.

Quando se equipara um sujeito ou sua ação a Hitler para descredibilizá-lo, mobiliza-se a cólera - "inclinação penosa para uma manifesta vingança de um desdém manifesto e injustificável de que nós mesmos ou nossos amigos fomos vítimas" (ARISTÓTELES, 2013, p. $123)$ - como recurso de adesão do "auditório". A força dessa paixão, segundo Aristóteles (2013, p. 123), reside no fato de que "todo sentimento de cólera [embora de natureza penosa] é sempre acompanhado de um certo prazer no antegozo da expectativa da vingança". Esse procedimento é denominado reductio ad Hitlerum - responsável por descredibilizar o outro pela mobilização da cólera - que pretendemos, agora, investigar ${ }^{4}$.

\section{Reductio ad Hitlerum: estratégia retórica da política e da religião}

Essa estratégia retórica é frequentemente retomada por Angenot em seu livro Rhétorique de la confiance et de l'autorité (2013) como uma ferramenta para a compreensão da retoricidade dos discursos contemporâneos. Titular da cátedra "James McGill d'Étude du Discours

\footnotetext{
${ }^{3}$ Voltaremos a isso mais adiante.

${ }^{4}$ Vale destacar que nosso interesse aqui não é acusar ou defender seja os evangélicos seja aqueles que mobilizam a reductio ad Hitlerum, mas compreender esse processo de construção retórica e seu funcionamento hoje. Isso atende, entre outros objetivos, à compreensão da importância da retórica para os estudos discursivos na atualidade.
} 
Social" na Université McGill em Montréal, M. Angenot possui uma obra vasta que aborda e articula diferentes campos do saber, como Retórica, História das Ideias, Análise do Discurso e Língua e Literatura Francesas. Seus estudos buscam descrever a tipologia dos discursos modernos, dos sistemas de crença das sociedades ocidentais e dos procedimentos retóricos da política.

Antes de prosseguir, cabe destacar que a reductio ad Hitlerum se relaciona intimamente com duas outras noções mobilizadas em seus trabalhos (ANGENOT, 2010; 2012; 2013): as religiões mundanas e o discurso social. A relação entre esses três elementos e sua produtividade para a análise e compreensão da formulação dos discursos modernos no âmbito político-religioso será desenvolvida a seguir.

Primeiramente, o sofisma ad Hitlerum é denunciado na obra do filósofo político de origem judaica Leo Strauss que, discutindo um dos preceitos da teoria sociológica weberiana - toda preferência, mesmo vil e insana, "deve ser julgada pelo tribunal da razão como tão legítima quanto qualquer outra preferência" (STRAUSS, 2014, p. 51) - afirma que se trata de uma ideia obscurecida pela figura de Hitler. O autor afirma que,

infelizmente, não é de todo inútil dizer que, ao longo de nosso exame, devemos evitar a falácia que nas últimas décadas tem sido frequentemente usada como um substituto da reductio ad absurdum: a reductio ad Hitlerum. Uma concepção não é refutada pelo fato de ela ter sido partilhada por Hitler. (STRAUSS, 2014, p. 52).

A reductio ad Hitlerum se constrói - a partir das concepções historicamente sedimentadas ao redor da figura de Hitler - como uma estratégia mobilizada para o debate e para o triunfo sobre o adversário. No livro VI de seu Organon, intitulado "Elencos sofísticos", Aristóteles (1999, p. 81-82) aborda os mecanismos que permitem ao orador vencer as disputas verbais. Trata-se da Erística, técnica de guerra argumentativa:

O que os Sofistas preferem é, com efeito, parecer que refutam a outra parte; a seguir, mostrar que o opositor comete um erro qualquer; em terceiro lugar, induzi-lo ao paradoxo; em quarto lugar, reduzi-lo ao solecismo [...] e, mas só por fim, levá-lo a repetir a mesma palavra uma e outra vez. 
Portanto, os propósitos dos que polemizam e estudam o modo de vencer as guerras verbais - a redarguição, a falsidade, o paradoxo, o solecismo e a redundância - não são argumentos demonstrativos, mas técnicas que indagam sobretudo o aparente, e não o real.

Da Antiguidade grega advém a distinção entre três técnicas do discurso, que compartilham formas comuns de raciocínio na medida em que nenhuma delas pode afirmar a partir de prova demonstrativa: a retórica - arte do orador, arte de discursar em público e influenciar um auditório -, a dialética - técnica da discussão serena entre indivíduos motivados por um mesmo desejo de buscar a verdade -, e a erística - arte da controvérsia, da disputa, técnica da "guerra" argumentativa. (ANGENOT, 2013, p. 325 , tradução nossa, grifos do autor).

Os trabalhos de Angenot, a partir das bases conceituais da Retórica clássica, buscam a compreensão daquilo que é regular nos discursos modernos, ou seja, inserem-se no que podemos chamar hoje de Retórica contemporânea. Isso significa operar deslocamentos nos conceitos extraídos do pensamento aristotélico segundo a natureza das "novas ideias" surgidas a partir da evolução das sociedades.

Uma dessas ideias, produzida a partir das consequências da Segunda Guerra Mundial, é a de que, como dito anteriormente, Hitler é um ser maligno. A partir dos acontecimentos do século XX, portanto, temos um parâmetro de referência retórica cujas figuras metafóricas giram em torno do personagem histórico que foi o Führer, bem como de suas ações:

Reductio ad Hitlerum é uma expressão irônica que designa, no latim de cozinha, o procedimento retórico que consiste em

\footnotetext{
${ }^{5}$ As "ideias" a que nos referimos remontam ao campo da História das Ideias e dos sistemas de pensamento. Angenot (2012, p. 3, tradução nossa) alerta para o fato de que "encontramos também, frequentemente, a expressão 'mecanismos mentais' - assim, o 'maniqueísmo' do qual falo [...] é de bom grado qualificado como 'mecanismo mental', julgado próprio a certas 'famílias de espírito', particularmente impregnadas de 'ideologia' em um de seus sentidos, pejorativo, dessa palavra”. Essa reflexão será importante para compreendermos os processos de associação semântica, de um lado, do nazismo ao "mal", e, de outro, dos cristãos ao "bem".
} 
desqualificar os argumentos de um adversário ou em caluniar sua pessoa e seus atos, associando-os em alguma medida a Adolf Hitler ${ }^{6}$. É um decalque humorístico da reductio ad absurdum. (ANGENOT, 2013, p. 353, tradução nossa).

É uma lógica falaciosa, um argumento com peso emocional (que, ao ser mobilizado, desperta as paixões, ou pathos, isto é, certas disposições de espírito na plateia) recorrente em culturas nas quais qualquer relação com Hitler ou nazistas é de antemão condenada. Essa tática, sabe-se, é utilizada para desqualificar argumentos do oponente ou quando não há mais argumentos. Sublinhamos também a conhecida Lei de Godwin, ou "regra das analogias nazistas", que tem por base a seguinte afirmação feita em 1990 por Mike Godwin (1994, tradução nossa) 7. "à medida que cresce uma discussão on-line, a probabilidade de surgir uma comparação envolvendo nazistas ou Adolf Hitler se aproxima de 1 (100\%)" (tradução nossa). Portanto, considera-se que "perdeu a discussão" quem usou essa comparação em um argumento, pois essa tática é muito mais agressiva e tida como "desleal", na medida em que se presta a denegrir ou desautorizar ética e moralmente aquele a quem se dirige.

Essa associação tem como base a construção histórica da memória do nazismo, caracterizado hoje como regime "totalitário". A própria expressão "totalitarismo" era um neologismo na época: tornou-se um conceito global que designa o horror político inventado no século XX. "Totalitarismo", em função desses fatores, tornou-se um idealtype, um termo abstrato cujos processos de formulação caracterizam as ciências humanas, ou seja, é um processo recorrente a transformação de fatos históricos em tópicos retóricos, em conceitos abstratos, em ideias colocadas em debate no discurso. Angenot (2010, p. 2, tradução nossa, grifo do autor) afirma que "seria preciso elaborar uma genealogia intelectual do Mal e encontrar um conceito sintético que transcenda essas ideologias particulares e lhes atribua, se me for permitido dizer, ab ovo uma singularidade perversa". A partir dessas reflexões, Angenot esboça o histórico de um paradigma abundantemente atestado: aquele que explica a infelicidade do século pela "sacralização do político".

${ }^{6} \mathrm{~A}$ expressão foi reutilizada mais tarde pelo filósofo especialista de Shoah George Steiner.

${ }^{7}$ Procurador e autor norte-americano. 
Alertando para o fato de que os personagens mais perversos da época de Shakespeare se satisfaziam com uma dúzia de cadáveres, Angenot (2010) busca descrever a ideia do Mal forjada nos regimes totalitários que, seguindo uma outra lógica perversa, acumularam milhões de vítimas. São sistemas, segundo ele (2010, p. 3, tradução nossa), cuja ideologia toma um sentido de "sistema total", que explicam todas as condições da história humana, "o Weltanschauung, como diziam os nazistas". Ora, um sistema ideológico que explica o presente, o passado e o futuro é uma "religião nova", que tomou forma em contextos de regimes totalitários, e por isso podem ser designados como "religiões mundanas", "seculares" ou "políticas". A natureza dessas religiões, bem como as ideias de que são compostas, são estudadas de forma mais sistemática pela História das Ideias:

O historiador das ideias é confrontado constantemente com a obsolescência do conveniente e do racional. O passado é um vasto cemitério de "ideias mortas" produzidas por pessoas desaparecidas, ideias que foram, no entanto, tomadas, em outro momento ou recentemente, como convincentes, comprovadas, adquiridas, assim como importantes, mobilizadoras etc. (ANGENOT, 2012, p. 1, tradução nossa).

Portanto, a sacralização das ideologias políticas foi responsável pela adesão de uma parcela considerável de cidadãos que aprovavam e reproduziam as ideias de Hitler nos anos 1920 na Europa. Nesse recorte temporal, já observávamos uma integração das esferas políticas e religiosas, uma vez que o regime nazifascista possuía seus dogmas de base. A ideia da "pureza" da raça ariana, por exemplo, legitimaria o preconceito contra os judeus. A ideologia que se instalou em Berlim no começo do século XX e que culminou na Segunda Guerra Mundial integrou

um discurso holomorphe, que diz a verdade do homem, revela seus destinos, diagnostica o mal social, encontra sua causa, formula o remédio, indica a missão dos justos na história, um sistema que tem como lema "a busca incessante das condições da verdade integral, da justiça indefectível. (ANGENOT, 2010, p. 3, tradução nossa). 
Desse modo, compreendemos por que o fascismo foi classificado por autores posteriores como uma "religião secular": essa expressão é paradoxal em termos retóricos, pois o adjetivo "secular" parece contradizer a essência semântica do substantivo "religião". Esse sintagma nominal convoca uma expressão conhecida no âmbito religioso: a Religio perennis, isto é, a perenidade transhistórica do fato religioso e de uma antropologia da incompletude humana.

O "discurso social", por fim, representa toda uma teoria elaborada a partir de uma análise sistemática dos discursos de 1889 (ANGENOT, 1989), que se pautou na pesquisa do homogêneo, na demonstração do que é regular e recorrente por trás das variações, e quais são as regras predominantes de cognição e de discursivização por trás da diversidade das escrituras:

Em outras palavras, esse processo consistiu em pesquisar as legitimações, as dominâncias e as recorrências do homogêneo na cacofonia aparente, dos princípios de coesão, de restrições e de aglutinações que fazem com que o discurso social não seja uma justaposição de formações discursivas autônomas, estritamente fechadas sobre suas tradições próprias, mas um espaço de interações em que as restrições, as imposições de temas e de formas venham preencher as brechas, opor-se às tendências centrífugas, trazer ao Zeitgeist uma espécie de unificação orgânica, fixar entropicamente os limites do que pode ser pensado, do que pode ser argumentável, do que pode ser narrado, do que pode ser escrito. (ANGENOT, 1989, p. 11-12, tradução nossa).

A hegemonia discursiva é composta por regras que regulam o dizer e restringem o novum, ou seja, ela é composta por determinações que - aquém e além do que é dito, das posições enunciativas, das formações discursivas e das ideologias - disponibilizavam de antemão essas possíveis formulações, fazendo que os contradiscursos ou as vozes contrárias a certo estado de coisas, de pensamentos e de ideias sejam na verdade um mecanismo do próprio dispositivo de discurso social.

Assim, duas noções são muito importantes para o entendimento do discurso social: de um lado, temos a hegemonia, "compreendida como a resultante sinérgica de um conjunto de mecanismos unificadores e reguladores que asseguram, simultaneamente, a divisão do trabalho discursivo e a homogeneização das retóricas" (ANGENOT, 1989, p. 12, 
tradução nossa); e, de outro lado, as dissidências, isto é, certas rupturas dóxicas ou epistêmicas, pontos em que a malha sociodiscursiva se desfaz e pelos quais, através de um furo, acreditamos ver aparecer outra lógica. Angenot (1989) acredita que esses enunciados dissidentes (tratados pelo autor como heteronomias) existem somente a partir de uma observação preliminar dos fatos retóricos, na teoria.

Convencionamos chamar heteronomias, nessa problemática, o que, no discurso social, escaparia à lógica da hegemonia. Nós pesquisaremos não somente as simples divergências de opinião ou inovações formais que permanecem no quadro das combinações permitidas, mas fatos que se situariam fora da aceitabilidade e da inteligibilidade normais situadas pela hegemonia. Por ora, essas heteronomias são apenas postuladas. (ANGENOT, 1989, p. 13, tradução nossa, grifos do autor).

Isso acontece porque há, segundo as configurações do discurso social, uma resistência natural ao novum, isto é, ao enunciado novo, ao noch nicht Gesagtes ("ainda não dito"). Esse enunciado novo estaria fora do próprio sistema de regras de enunciabilidade social. Por esse motivo, o déjà-dit se instaura como matriz do dizível que tem como princípio o resgate de uma memória.

Quando, pela atribuição jornalística, Frei Betto associa a Bancada Evangélica à figura de Hitler, comparando-a com o "ovo da serpente" dos anos 1930, percebemos não somente o resgate de uma memória e de suas valorações, como também se revela a tática de desqualificação, como a construção de lugares determinados de fala. A observação dos comentários em redes sociais escritos a partir dessa associação revela sem grandes dificuldades esses dois lugares que se interpenetram: de um lado, temos aqueles que defendem a Bancada Evangélica, rejeitando a associação com Hitler; de outro, temos aqueles que reafirmam, repetem, reproduzem essa associação. Esses dois lugares argumentais, segundo o princípio de oposição às forças centrífugas do discurso social, já estão previstos em seu próprio dispositivo:

O discurso social, em sua diversidade falsamente cintilante, seria somente um dispositivo implacável de monopólio da 
representação, em que toda divergência seria rapidamente recuperada, neutralizada, amenizada a despeito dela mesma, contribuindo para a reprodução indefinida dos poderes simbólicos. (ANGENOT, 1989, p. 13, tradução nossa, grifos do autor).

A partir dessas considerações de cunho teórico e histórico, intencionamos agora verticalizar a análise que foi por nós apontada: o desenvolvimento da ideia de "ovo da serpente", cuja enunciação ocorreu em 2013, alguns meses antes das últimas eleições presidenciais do Brasil.

\section{Metáfora e metonímia como figuras retóricas da reductio ad Hitlerum}

Ao retomar Jakobson e suas considerações a respeito da metáfora e da metonímia, Fiorin (2014a) demonstra que boa parte das figuras de retórica derivam dessas duas figuras basilares que dizem respeito à construção do sentido por similaridade e/ou contiguidade. De acordo com o autor, não necessariamente essas duas direções de sentido se excluem mutuamente.

Vale destacar ainda que Fiorin (2014b, p. 65) aponta para o fato de os estudos retóricos se apresentarem como relevantes para os estudos discursivos de maneira geral:

Se a retórica estudou, de um lado, a construção discursiva dos argumentos e, de outro, a dimensão antifônica dos discursos, as teorias do discurso devem herdar a retórica. Que quer dizer, no entanto, herdar a retórica? Lê-la à luz dos problemas teóricos enunciados na atualidade.

Sob esse aspecto, aproveitamos essa possibilidade apontada pelo autor para introduzir, aqui, o conceito de interdiscurso, uma das pedras de toque da Análise do Discurso de linha francesa, que é indispensável para a compreensão da metáfora não apenas como mecanismo cujo funcionamento depende exclusivamente dos elementos “internos” à língua, ou seja, uma "figura em si mesma", mas como resultante também do funcionamento do interdiscurso. De acordo com Pêcheux (2011, p. 158, grifos do autor),

o interdiscurso, longe de ser efeito integrador de discursividade torna-se então seu princípio de 
funcionamento: é porque os elementos da sequência textual, funcionando em uma formação discursiva dada, podem ser importados (meta-forizados) de uma sequência pertencente a uma outra formação discursiva que as referências discursivas podem se construir e se deslocar historicamente.

Deriva do que foi dito acima que a metáfora pode ser abordada por meio de, pelo menos, dois aspectos: i) interno: naquilo que a constitui enquanto materialidade linguística no nível do intradiscurso; ii) externo: naquilo que constitui uma rede de memória que possibilita o deslocamento de determinadas estruturas em diferentes condições históricas de produção. Nosso objetivo, portanto, atende à premissa do funcionamento do interdiscurso na construção da metáfora e da estratégia retórica. Esse jogo remissivo, para além da própria força argumentativa da "metáfora em si", reforça-a ainda mais pela recuperação de outras condições de produção discursivas: hoje, a Bancada Evangélica; antes, o nazismo; em uma antiguidade mais remota, César. Eis, na esteira daquilo que Braudel (1958) denomina "dimensão do acontecimento", "média duração" e "longa duração", o que a imagem do "ovo da serpente" metaforiza.

O sintagma "ovo da serpente", que reapareceu recentemente, foi enunciado por Frei Betto como parte de sua fala, que foi retomada por pelo menos dois meios de circulação: i) um meio que se apresenta como Pontifício, ou seja, reconhecido oficialmente pela Igreja Católica e pelo papa: as Pontifícias Obras Missionárias (www.pom.org.br). Nesse site, a matéria analisada é assinada por Jaime C. Patias; ii) um site assinado por Paulo Lopes (www.paulopes.com.br), cuja repercussão se deu não raras vezes nas redes sociais.

O período de publicação dos dois artigos em que a expressão "ovo da serpente" - que teria sido dirigida à Bancada Evangélica por Frei Betto - aparece foi novembro de 2013, alguns meses antes da corrida presidencial de 2014. Na matéria de Paulo Lopes, emprega-se a expressão "ovo do nazismo" como variante do sintagma atribuído a Frei Betto, discursivizada pela posição do jornalista.

A partir dessa explicitação das condições de produção desse enunciado, destacamos um primeiro aspecto do objeto analisado: trata-se de uma expressão retomada pelos elaboradores das matérias e atribuída, por meio do discurso direto, à figura de Frei Betto. Evidentemente, nossa questão aqui não é "jurídica", ou seja, não estamos advogando a favor ou contra as notícias ou a pessoa física de Frei Betto, mas observando que 
esses aspectos são fundamentais para o processo de análise dos efeitos de sentido produzidos pela construção metafórica. Assim, no jogo que constitui o lugar de "quem disse", ocorrem deslizamentos entre o lugar do "jornalista" e o do "religioso" e, com relação a este último, destaca-se ainda a hibridez de sua posição, ao mesmo tempo eclesiástica e política. Assim, destacamos as seguintes sequências discursivas:

SD1: "O escritor e teólogo Frei Betto disse que a bancada evangélica - um movimento político-religioso fundamentalista, ressaltou — ameaça a democracia brasileira porque equivale ao 'ovo da serpente' dos anos 30 do qual nasceu o nazismo.” (LOPES, 2013).

SD2: "Precisamos abrir o olho porque está sendo chocado no Brasil o poder fundamentalista de confessionalização da política", afirmou. "Isso vai dar no fascismo." (BETTO apud PATIAS, 2013).

SD3: "Estamos assistindo certos seguimentos religiosos a começarem a chocar o ovo da serpente, expressão que vem do nazismo dos anos 30 (do século passado) na Alemanha. Depois que a coisa esquentou é que muita gente se deu conta. No Brasil hoje, seguimentos religiosos estão cada vez mais partidarizados. Existe no Congresso Nacional a bancada Evangélica. Não tenho nada contra os Evangélicos, tenho contra essa bancada." (Ibid., 2013).

A expressão "ovo da serpente" nessas sequências está associada ao significado de "gestação", "estar em germe", "estado de latência", "projeção futura". E essa similaridade semântica que "autoriza" o uso da expressão e lhe confere força argumentativa. Do ponto de vista da metáfora há, portanto, uma rede parafrástica que permite a reescrita do enunciado "estamos assistindo certos seguimentos religiosos a começarem a chocar o ovo da serpente" sob formas como "estamos assistindo certos seguimentos religiosos a começarem a germinar/gestar/ despotencializar/atualizar o ovo da serpente". Nesse quadro, "Bancada Evangélica" está metaforizada pela figura da "serpente" e mantém com ela o sentido de "perigo", "mal", "malignidade".

${ }^{8}$ Entendido aqui, genericamente, como posição-sujeito produtora da matéria jornalística. 
Há não apenas uma rede de sentidos associada a "estado embrionário", do ponto de vista da condição do termo "ovo", como também uma outra associada ao estado de devir. Aquilo que está "sendo chocado", ou na "casca do ovo", é algo que se presta a negar o presente e a afirmar o futuro. Por contiguidade, poderíamos extrapolar o limite da metáfora e compreender a figura do "ovo" também como metonímia - de tipo relacional símbolo/aquilo que é simbolizado - para o tempo. Nesse sentido, "ovo" simboliza, por difusão semântica, o tempo.

Metáfora do "estado germinal" e metonímia do tempo, o termo acima destacado é de um tipo particular: não se trata de um "ovo" qualquer, mas "da serpente". A serpente, no sintagma "ovo da serpente", metaforiza o perigo e está, como dito anteriormente, vinculada à Bancada Evangélica. Mas perigo de quê? Do que virá; do filho prometido de uma gestação maligna; da volta do nazismo e da ascensão da maldade ao poder. Desse modo, produz-se o efeito de sentido de que, no futuro, o país será regido pelo ódio. A Bancada Evangélica, a partir dessas associações semânticas e históricas, será veículo de ódio, intolerância e de despotismo. Ironicamente, a marca da estratégia reductio ad Hitlerum é definida por Angenot (2013) como uma forma de apelar para a cólera do auditório, ou seja, constrói-se um discurso que acusa o outro por incitar o ódio e por tê-lo como bandeira política, mas mobiliza-se justamente essa paixão no auditório por meio de uma estratégia retórica.

No entanto, o emprego de "ovo da serpente" na história ocidental não foi feito pela primeira vez em 2013, no Brasil do então primeiro mandato da Presidente Dilma Rousseff. Vale destacar que, direta ou indiretamente, a fala atribuída a Frei Betto também emerge como elemento discursivo que participa de uma "campanha política" mais ampla em prol da reeleição daquela que seria, nas eleições de 2014, a representante máxima do poder político nacional. É nesse sentido que dissemos anteriormente que as sequências discursivas que abordamos aqui são enunciadas de um lugar heterogêneo em que o lugar do jornalista se mescla ao de Frei Betto, que fala de um lugar simultaneamente político e religioso. A mensagem é, ao mesmo tempo, informativa - "saibam que Frei Betto disse isso" -, emotiva - "não podemos compactuar com aqueles que representam hoje, no Brasil, aqueles outros que assassinaram milhares de inocentes" - e apelativa - "não votem nos candidatos da Bancada Evangélica". Acrescenta-se a isso que, por outros meios, a figura de Frei Betto está associada a uma 
certa "esquerda partidária". Outros enunciados, que não analisaremos aqui, estão disponíveis no YouTube (SCAVONE, 2015) e, neles, Frei Betto afirma também ter ajudado na construção - através de seu trabalho pastoral - do Partido dos Trabalhadores, embora reconheça nunca ter se filiado ao partido.

A partir dessas considerações, alguns entimemas podem ser depreendidos:

a) Pela afirmação:

Proposição 1: X é nazista;

Proposição 2: Y vota em X;

Conclusão: $\mathrm{Y}$ é nazista.

b) Ou ainda, por seu "contrário":

Proposição 1: $\mathrm{X}$ é cristão;

Proposição 2: Y vota em X;

Conclusão: $\mathrm{Y}$ é cristão.

Em (a), ser nazista é negativo e, em (b), ser cristão é positivo. Nessa estrutura, um é contrário do outro na mesma proporção em que o "bem" se opõe ao "mal". Ao observarmos algumas opiniões compartilhadas pertencentes à doxa, isto é, ao senso comum, temos que, de um lado, os nazistas são denotados por todos aqueles que sentem ódio, que oprimem as minorias e que agridem os inocentes: por isso esse rótulo possui um sentido disfórico. Por outro lado, os cristãos denotam todos aqueles que sentem amor, que respeitam as diferenças e que protegem os inocentes: assim, esse rótulo possui um sentido eufórico. Em nosso momento presente, temporalidade em que o discurso do Frei Betto se constrói, sua imagem de enunciador (seu ethos) é apresentada como a de um "cristão autêntico", ou seja, aquele que zela pelo amor e pela igualdade, enquanto os outros, representados pela Bancada Evangélica, são falsos cristãos, de modo a ser associados, nas sequências discursivas analisadas, aos nazistas. A partir delas, pode-se deduzir a seguinte interpelação: "Ei, vocês, vão votar em quem?".

Dissemos anteriormente que a expressão "ovo da serpente" não foi empregada pela primeira vez em 2013. Com efeito, sua utilização tem raízes mais profundas, e é nesse sentido que sua discursivização ganha ainda mais força no funcionamento do interdiscurso (PÊCHEUX, 2011). 
Inicialmente, podemos delimitar a obra Júlio César, de Shakespeare, em que o personagem Bruto faz a seguinte ponderação:

BRUTO: Preciso é que ele morra. Eu, por meu lado, razão pessoal não tenho para odiá-lo, afora a do bem público. Deseja ser coroado. Até onde influirá isso em sua natureza, eis a questão. É o dia claro que as serpentes chamam, aconselhando-nos a andar com jeito. Ele, coroado? Sim, mas é certeza com isso darmos-lhe um ferrão, que o deixa capaz de realizar o mal que entenda. A grandeza exorbita, quando aparta a consciência o poder. Para ser franco com relação a Cesar, nunca soube que as paixões ou a razão nele tivessem qualquer preponderância. Mas é coisa sabida em demasia que a humildade para a ambição nascente é boa escada. Quem ascende por ela, olha-a de frente; mas, uma vez chegado bem no cimo, volta-lhe o dorso, e as nuvens, só, contempla, desprezando os degraus por que subira. Cesar assim fará. Antes que o faça, será bom prevenir. E, como a luta não poderá alegar o que ele é agora, argumentemos que se a sua essência vier a ser aumentada, é bem possível que incorra em tais e tais extremidades. Consideremo-lo ovo de serpente que, chocado, por sua natureza, se tornará nocivo. Assim, matemo-lo, enquanto está na casca. (SHAKESPEARE, s/d, p. 35-36).

Ou seja, na peça shakespeariana, a metáfora emerge para argumentar contrariamente à coroação de César como imperador. Contra essa possibilidade, Bruto adota um discurso de prevenção: "matemo-lo enquanto está na casca". Sob esse prisma, essa primeira ocorrência da expressão participa de uma esfera de conspiração que visa à "eliminação do mal" antes que ele esteja forte demais para ser evitado. É somente após esse jogo de retomadas que é possível associar à ideia de "mal em germe" as figuras do nazismo e dos candidatos evangélicos. O que era essencial no discurso conspiratório de Bruto permanece: "o mal é iminente e é preciso contê-lo antes que seja tarde".

Essa ideia de base será retomada posteriormente por Bergman em seu filme $O$ ovo da serpente (1977), em que o diretor nos apresenta o contexto de instauração do nazismo na Alemanha. Trata-se de uma narrativa que apresenta o percurso de dois irmãos trapezistas que 
trabalhavam em um circo na Berlim dos anos 1920. Logo no início do filme, o irmão de Abel Rosenberg (David Carradine) se suicida com um tiro na boca. No percurso de descoberta de Abel pelos motivos da morte do irmão - que tem como pano de fundo a Berlim hiperinflacionada do início do século - o personagem depara com uma série de experiências laboratoriais feitas em cobaias humanas. É esse contexto de crise políticoeconômica e de desenvolvimento de experiências comportamentais que começa a "chocar o ovo da serpente" na Alemanha. A metáfora retorna, assim, nos anos 1970, para descrever o estado em que se encontrava a Berlim do início do século XX. A atmosfera de incerteza e de caos na Alemanha é a incubadora que "choca o ovo da serpente":

Este filme deve, portanto, decorrer entre sombras, isto é, na realidade das sombras. Tudo é uma maldição, e faz frio naquele inferno porque não há com que fazer fogo. É novembro de 1923, o dinheiro tem o valor de seu peso em papel, pois está tudo de pernas para o ar. (BERGMAN, 1996, p. 191).

Todo esse percurso histórico do termo "ovo da serpente" sofre uma condensação quando empregado em uma atualidade, ou seja, sofre uma redução que resgata as regiões do sentido mais evidentes e sedimentadas a respeito do fato histórico: a opinião compartilhada de que o nazifascismo foi um regime maligno.

Não é sem razão que a reductio ad Hitlerum deriva da reductio ad absurdum: nesta estratégia, pretende-se demonstrar que uma proposição é verdadeira mostrando-se que um resultado absurdo, insustentável ou falso deriva de sua negação; ou então trata-se de demonstrar que uma proposição é falsa mostrando-se que um resultado absurdo, insustentável ou falso deriva de sua aceitação. Por exemplo, o argumento apagógico "fumar não pode ser um mal. Hitler não fumava. O trânsito é um mal, porque muitas pessoas perdem a vida em acidentes. Se não houver trânsito não haverá mortes. Então, vamos proibir a circulação para salvar vidas" (FIORIN, 2015, p. 143) é um exemplo do emprego ad absurdum, já que notamos um raciocínio ("fumar não pode ser um mal, mas o trânsito sim") em que se deriva uma proposição de uma premissa, mostrando que ela é falsa. Da mesma forma, a tentativa de comprovação ou refutação de uma proposição através de sua associação com Hitler demonstra, de imediato, 
um direcionamento da atenção da plateia para a emoção (cólera) e para o absurdo da negação dessa proposição para um cristão: "A Bancada Evangélica não é a gestação do mal e não é um perigo para o futuro", logo "votem nos membros da Bancada Evangélica". Esse procedimento desvia e mascara a natureza dialética de um discurso em função de seus procedimentos retóricos, ou seja, pelas consequências de tais associações.

\section{Considerações finais}

Em suma, esse percurso trilhado por nós para a análise de uma expressão enunciada pela figura de Frei Betto - resumido na localização dos estudos retóricos entre as ideias linguísticas, depois no funcionamento da estratégia reductio ad Hitlerum no interior e no exterior do sistema da língua e, por fim, em uma reflexão aprofundada sobre essa estratégia a partir dos mecanismos basilares de configuração de sentido (a metáfora da gestação e a metonímia do tempo) tratados por Fiorin (2014a) - permitiu-nos a apreensão da retoricidade tanto da esfera política - a natureza de associação de sentidos considerados historicamente disfóricos para uma parcela dos integrantes do Congresso Nacional, denominada Bancada Evangélica, em um momento que precedia as eleições presidenciais de 2014 - quanto da esfera da religião - a partir da mobilização de mecanismos de convencimento dos potenciais eleitores em função de suas crenças religiosas. A retoricidade, como vimos, emergiu de um terreno indefinido composto pela fusão de diversas esferas do discurso. É desse modo, a partir dos limites tênues entre o campo político e o campo religioso, que o sintagma "ovo da serpente", tal como foi enunciado em 2013, produziu seus efeitos de sentido no discurso.

Frei Betto, em seu pronunciamento, empregou uma estratégia de grande peso emocional e atingiu os efeitos esperados: "O antifascismo da Segunda Guerra Mundial legou à esquerda posterior a 1945 uma categoria nebulosa em perpétua expansão, um 'fascismo' sem margem que ia se tornar a 'injúria suprema' semeada ao vento" (ANGENOT, 2013, p. 347, tradução nossa).

Neste trabalho, não esgotamos os procedimentos retóricos disponíveis em listas seculares de técnicas do discurso falado. Alguns deles são mencionados por Angenot (2013), como os sofismas ad baculum (uma forma de raciocínio que visa a reduzir o interlocutor ao 
silêncio), ad metum (a especulação sobre as consequências lamentáveis da medida atacada), ad referentiam (a exigência da submissão pelo receio respeitoso) e o argumentum ad consequentiam (o destaque sobre os riscos inerentes à sustentação de tal tese), entre outros. A escolha de um desses argumentos - ad Hitlerum - revelou a profundidade desse mecanismo da fala e permitiu uma melhor compreensão da natureza dos discursos que circulam na mídia hoje.

\section{Referências}

AMOSSY, R. (Org.). Imagens de si no discurso: a construção do ethos. São Paulo: Contexto, 2008.

ANGENOT, M. La parole pamphlétaire. Paris: Payot, 1982.

. Hégémonie, dissidence et contre-discours: réflexions sur les périphéries du discours social en 1889. Études littéraires, v. 22, n. 2, p. 11-24, 1989.

Religions séculières, totalitarisme, fascisme: des concepts pour le XXème siècle. Discours Social, Montréal, v. 20, p. 5-38, 2010.

. La notion d'arsenal argumentatif: l'inventivité rhétorique dans 1'histoire. Rétor, v. 2, n. 1, p. 1-36, 2012.

. Rhétorique de la confiance et de 1'autorité. Discours Social, Montréal, v. 44, 2013.

ARISTÓTELES. Organon. São Paulo: Nova Cultural, 1999. (Coleção Os Pensadores).

. Retórica. São Paulo: Edipro, 2013.

BERGMAN, I. Imagens. Tradução de Alexandre Pastor. São Paulo: Martins Fontes, 1996.

BRAUDEL, F. Histoire et sciences sociales: la longue durée. In: Annales - Histoire, Sciences Sociales, ano 13, n. 4, p. 725-753. Paris: EHESS, 1958.

FIORIN, J. L. Figuras de Retórica. São Paulo: Contexto, 2014a.

. Argumentação e discurso. Bakhtiniana, São Paulo, v. 9, n. 1, p. 53-70, 2014 b.

. Argumentação. São Paulo: Contexto, 2015. 
GODWIN, M. Meme, counter-meme. Wired. 10 jan. 1994. Disponível em: <http://www.wired.com/1994/10/godwin-if-2/>. Acesso em: 4 maio 2016.

LOPES, P. Bancada Evangélica é ovo do nazismo, afirma Frei Betto. In: Paulopes. 20 nov. 2013. Disponível em: <http://www.paulopes.com. br/2013/11/bancada-evangelica-eh-ovo-do-nazismo-diz-frei-betto.html\#. VZvaleuYVtQ>. Acesso em: 7 jul. 2015.

O ovo da serpente. Direção e roteiro: Ingmar Bergman. Estados Unidos da América; Alemanha Ocidental: Dino De Laurentiis Corporation, 1977. 119 min. son. color.

PATIAS, J. C. Fé e política: "toda a vivência da fé tem uma repercussão política", afirma Frei Betto. In: Pontifícias Obras Missionárias. 16 nov. 2013. Disponível em: $<$ http://www.pom.org.br/index.php?option=com content\&view=article\&id=2554:toda-a-vivencia-da-fe-tem-umarepercussao-politica-afirma-frei-betto\&catid=16:nacionais \&Itemid=75> Acesso em: 7 jul. 2015.

PÊCHEUX, M. Análise automática do discurso. Campinas: Pontes, 1997. . Metáfora e interdiscurso. In: . Análise de Discurso: Michel Pêcheux. Tradução e escolha dos textos por Eni Puccinelli Orlandi. Campinas: Pontes, 2011. p. 151-162.

SCAVONE, A. Depoimento de Frei Betto no debate promovido pelo PSOL. 21 mar. 2015. Disponível em: <https://www.youtube.com/ watch?v=U1MWdoh8JH8>. Acesso em: 5 maio 2016.

SHAKESPEARE, W. Júlio César. Edição de Ridendo Castigat Mores. Disponível em: <http://www.ebooksbrasil.org/adobeebook/cesar.pdf>. Acesso em: 11 jul. 2015.

STRAUSS, L. Direito natural e história. Tradução de Bruno Costa Simões. São Paulo: Martins Fontes, 2014. 